\title{
FACTORS INFLUENCING THE EFFECTIVE LEADERSHIP SUCCESSION PLANNING: STUDY ON A MALAYSIAN GLC
}

\author{
Shamsulkahar Abdul Shukor ${ }^{*}$, Suhaidah Hussain ${ }^{1}$ \\ ${ }^{1}$ Faculty of Industrial Management, Universiti Malaysia Pahang, Malaysia
}

ABSTRACT - The scope of this research paper is to study on the factors influencing effective Leadership Succession Planning (LSP) of one of the main Government Linked Companies (GLC). Background of the study provides an understanding on the external factors as well that have an influence on the topic of study, which covers among others, on the Malaysian economic policy itself. This study is aimed to study the current factors and the gap that is influencing the effectiveness of current LSP initiatives by a service oriented of Malaysian Government Linked Company, and to highlight some key critical factors as proposed in the literatures. Factors influencing the effectiveness of LSP are also subject on the ability of the leaders to adopt to external changes particularly in the era of borderless economic and faster rate of technology changes, and there are some differences from one organization to another, subject to the nature of the business and their stakeholders. However, there are some common important factors can be used as guidelines and practices particularly from the research literatures. Therefore, qualitative study was conducted to be carried out to fulfill the objectives and to answer the research questions. An interview with the Group Chief Executive Officer (CEO) of one GLC, who is the subject matter expert. The recording from the interview was transcribed and further analyzed using ATLAS.ti software. The findings evidence that there are current practice of leadership succession planning in the company, anyhow there is a gap between the aspirations of the Group CEO and the availability of $\mathrm{C}$-level replacement from within, and between the reality and the theories. Results of the findings identify the outcomes that need to be taken into action for a more effective LSP program. In the future, similar research approach can be conducted to other GLCs in order to analyze the similarities and complimentary aspirations with regards to LSP.

ARTICLE HISTORY

Received: 29-08-2019

Accepted: 06-11-2019

KEYWORDS

Leadership succession planning; Malaysian

government linked company

\section{INTRODUCTION}

Leaders in any organizations may come and go, but the organizations itself need to continue to exist and grow, particularly business organizations which existence is dependent on their business revenue. The leaders are be held responsible to ensure to ensure the continuity and growth of their companies. In view of this, owners or leaders of business organizations including stakeholders and Board of Directors, must have the awareness and need to know how to best develop it across all C-levels, in order for the organization to survive and thrive. Leadership Succession Planning (LSP) is key processes in assessing and developing an organization's leadership talent (Lewis \& Heckman, 2006).

Continuous performance of business organizations which is much dependent on the strong leadership, becomes the focus of interest of various references by many. Findings by literatures stated that transformational, well trained and proactive leadership influences organizational performance positively (Avey, Avolio, \& Luthans, 2011; Carmeli, Schaubroeck, \& Tishler, 2011; García-Morales, Jiménez-Barrionuevo, \& Gutiérrez-Gutiérrez, 2012).

Besides the business operation knowhow, the C-level leaders of the business organizations should be able to manage the dynamism and complexity of business challenges particularly external factors. The leaders must be able to always updating their strategic business planning using measurement such as PESTLE, which is developed to evaluate the impact of 'Political, Economic, Social, Technological, Environmental and Legal' factors (Rastogi \& Trivedi, 2016).

\section{Background of the Study}

Malaysian economic by some extent is partly moved and influenced by Government-Linked Companies (GLC) . Malaysian government, through its formed GLC, acquired large shareholding in some Malaysian companies particularly those provide utilities, goods and services to the general public, in meeting national aspirations, social needs and to ensure sustainability in facing global challenges (Centre for Public Policy Studies, 2006; Vietor, 2007; Beh, 2007).

Malaysia's GLCs function as part of the government's strategic move and mechanism to better manage its economic performance, in ensuring a balanced socioeconomic ingredients which include the fact of being a multi-racial nation, political factors, education and social well-being factors. 
For a start, researcher is interested in learning how LSP is practiced in one of the GLCs, by focusing on the effectiveness of the company's current LSP and what are the gap that exist between the current performance and the aspiration of its newly appointed Group Chief Executive.

\section{The Company}

Figure 1 shows the organization structure of the Company, as to give an idea how the C-level is structured. The biggest shareholder of this organization is Khazanah Holdings, an investment company wholly owned by Malaysia Government through Finance Department, which is $33.2 \%$ of the total quantity of 1.66 billion shares, followed by another Malaysian Government wholly owned organization namely Employees Provident Fund which is $10.8 \%$.

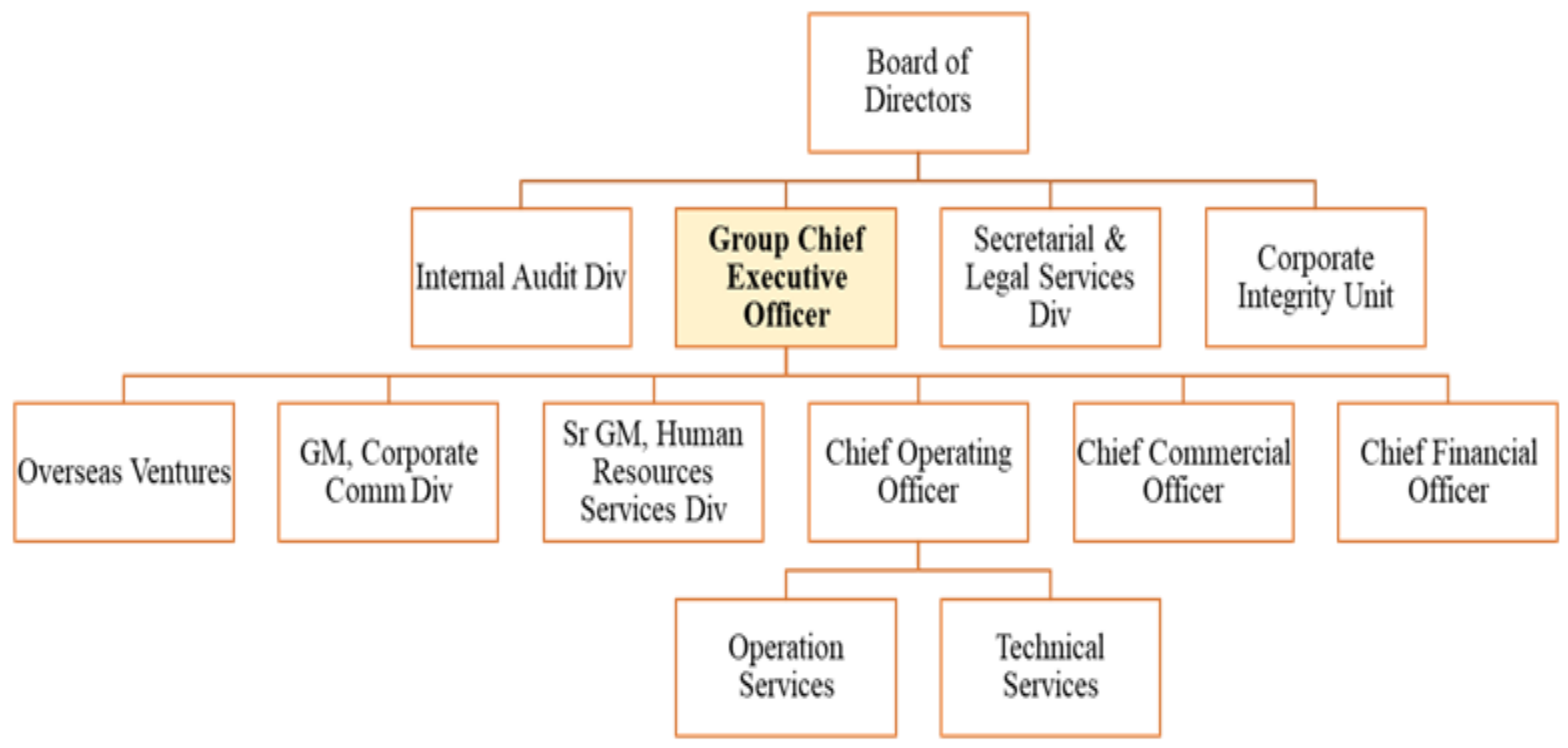

Figure 1: Organization Structure of the Company

Source: The Company's Website

In order to meet the expectation of their main stakeholders, particularly the government through Khazanah Holdings, GLC leadership requires the right candidate who have instituted a framework for investment decision making, that all investments and divestments having to go through several "decision gates," including the executive committee and a nine-member board, which is composed of a mix of renowned private sector personalities and senior relevant government officials (Hayat, 2013).

Situational Analysis and Challenges of GLCs

Leaders of the GLC must ensure that their companies enjoy continuous excellent financial performance and shareholders value, which is the government, even though the Company does not have competitors. Poor LSP will cause inefficiency of company performance which lead to some perception impact on the government integrity and on its business viability.

Malaysian Government own some percentage of ownership in the GLCs, and also has the final say on the appointment of GLC top management, through its investment arm Khazanah Holdings. Khazanah owns 36\% of the market capitalization of the Malaysian stock market in 2017, play a significant role in the development of the country's economy (Mokhtar, 2005).

Stringent processes is adopted in vetting candidates for the appointment of CEOs in GLCs. Proper recruitment procedures and techniques are already in place, in order to achieve transparencies and accountability of the appointments (The SUN, 2017). At the same time, political leaders must be clear about their involvement in making some very important decisions, among others, to be greater decentralization in the GLC's decision making to achieve faster implementation and effectiveness even though it may cause dilution of the federal government power (Malaysia National Economic Advisory Council, 2008).

Research Objectives

The objectives of this paper are:

i. To study the current practice of LSP of the Company

ii. To identify the factors influencing the effectiveness of LSP.

iii. To explore how LSP can be used as a developmental tool in attending the gap between reality and aspirations.

\section{LITERATURE REVIEW}

Leadership succession planning (LSP) become an important subject need to be taken into account by the stakeholders and top management of any organization, when they need to replace C-levels and when there is sudden requirement (Galagan, 2010; Bocatto, 2010). LSP is important for any organizational leaders and stakeholders as a pertinent tool in in 
preparing for future changes in employee demographic and to have preparation by developing the employees to assume leadership role (Calareso, 2013; Beheshtifar, 2012; Fink, 2011), and due to the fact that their companies have committed, dedicated and high-functioning trustees who work toward great outcomes for the plan (Brent, 2013).

\section{Existing LSP Sourcing Strategies}

Identifying and developing high potential internal employees becomes an integral tasks of organizational planning and performance (Risher, 2015; Yamkovenko \& Hatala, 2015). Competencies and skills of highly potential managers of the future leaders are critical components of LSP where the process need to be assessed accordingly and continuously (Moradi, 2014; Hanson, 2013). It is an important business sense for having list of internal candidates from time to time for the talent pipeline (Saratun, 2016). The company should be willing to invest in systematic and synergistic practices for sourcing high potential internal talent through LSP (Cho \& Poister, 2014).

When we talk about coaching, constant engagement in an active leadership development planning process with those high-potential managers brings about motivated and trust their higher level management particularly their mentors with their career progression (Saratun, 2016). Top management need to leverage it to motivate and develop future leaders, and executive coaching is one of the most effective method for developing high potential internal managers for multiple job levels and promotions (Chung, 2012).

\section{Addressing Gap in the Current LSP Implementation}

Leadership skills gap among the immediate subordinates to the C-levels, can be overcome and addressed through formal coaching and mentoring, series of relevant training, executive interviews (Stewart, 2016). Relationship building is fostered and nurtured while addressing development gaps and improving connection between performance and potential, can be developed during one-to-one session, as a transactional exchange of information between the top management and those high potential employees (Allio, 2012). Multigenerational workforce will lead in gaining the opportunities to take on special assignments to sharpen skills and wider exposure (Quintana, 2014), and meeting the needs of them to enrich new skills and capabilities and gain exposure to other leaders across the organization via cross training and talent awareness session (Dewah \& Mutula, 2014).

Remediation of their learning gaps via new skills exposure and development, improves performance where they will become more promotable employees thus creating a win-win culture and preparing LSP actual talent for the company (Blattner, 2015) and cultivating leadership skills makes employees from degrees of potential to emerge and shape as leaders (Jing \& Avery, 2016). Leadership gaps could also be reduced through the bi-directional relationship between potentials and top management, as they are to be accountable for sharpening, training and development of qualified highpotential managers though succession planning (Moradi, 2014).

\section{Meeting Organizational Needs}

It is a norm that the winning culture by achieving results needs to be tied up with the capabilities of high-potential employees and leaders by having a replacement planning strategies (Sheth, 2016). Another winning culture that benefits the organization and these high-potential employees can be generated via a cultivating replacement planning strategy (Nold, 2016).

LSP needs to have the preparation for the leaders to accomplish the organizational needs, to strive to accomplish organizational targets and goals (Metcalfe \& Metcalfe, 2013). The behavior of constant communication is also important to be cultured between leaders and high-potential employees linked and drives to the business needs affect its efficiencies and effectiveness, leads towards win-win workplace climate (Stumpf, JR, Ehr, \& Dam, 2016; Blattner, 2015; Quintana, 2014).

Business organizations must keep alert and be prepared in making operational decisions when it comes to external factors as well. Besides political changes as happened in Malaysia as happened in the recent General Election in May 2018 as discussed in Chapter 1, their potential leaders need to have pro-active ability to face the globalization openness market, disruption of technologies, and workforce. Rate of changes and external influences is unpredictable, urging the need for organizational agility that influence internal operation disruption (Bass, 2008; Ariss, Cascio, \& Paauwe, 2014; Greenhalgh \& Jantti, 2012).

\section{METHODOLOGY}

\section{Research Design}

Research design used for this study will apply qualitative research, which is usually considered as inductive, with the underlying assumptions being that reality is a social construct where it is difficult, complex and interwoven to measure its variables, that there is a primacy of subject matter and that the collected data shall consist of insiders' point of view and knowledge (Rovai, Baker, \& Ponton, 2014), which provide a content and context rich breadth of information is current and practical although subjective (Tracy, 2013), aimed at achieving deep understanding of a specific organization or event, instead of the surface description of a large sample of a population. Qualitative has five areas namely case study, ethnography study, phenomenological study, grounded theory study and content analysis (Bhawna \& Gobind, 2015).

This qualitative research applies exploratory type of research which is the method to clarify and define the nature of the problem in the research, while comparatively, descriptive research is to describe characteristics of the studied population or phenomenon, and causal research is carried out to study the link of cause-and-effect relationships among 
variables post-identification of the research problem (Zikmund, Carr, \& Griffin, 2013). Summary of common full research design and process is illustrated in Figure 3. 2 below.

\section{Conceptual Framework}

The following diagram as in 2 is the conceptual framework for the study, demonstrates three independent variables are identified and classified in answering the objectives and questions that testify the scope of the study's topic.

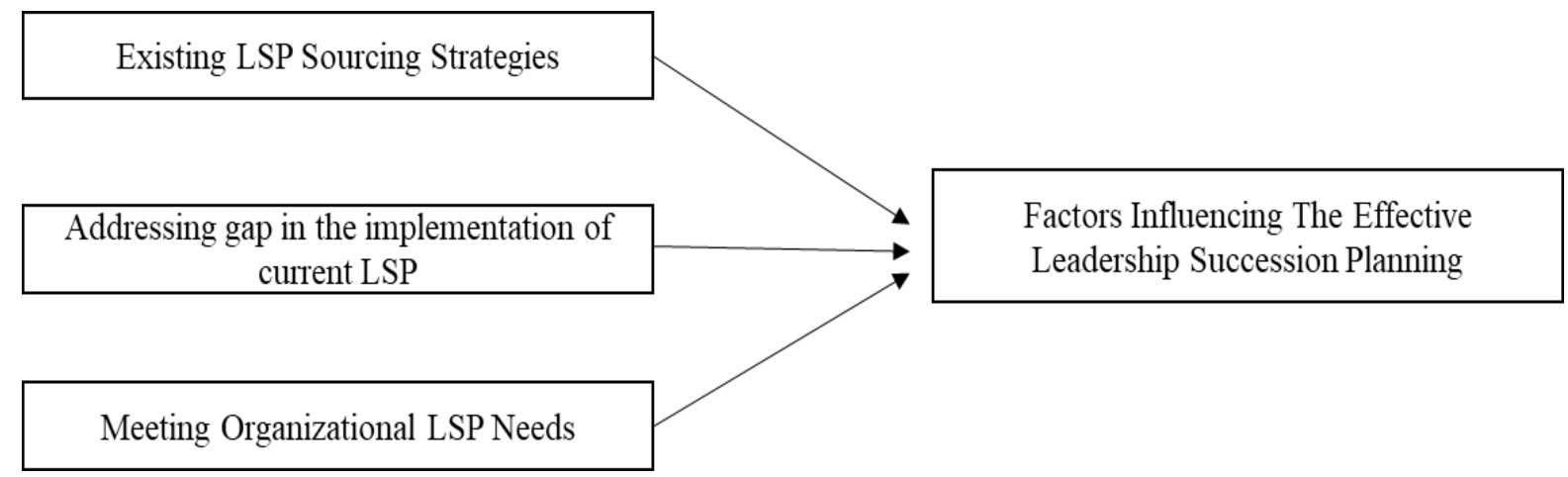

Figure 2: Conceptual Framework

\section{Data Collection}

Interview was conducted in this context can be understood as the nature of qualitative research. Types of interview are structured interviews, unstructured interviews and semi-structured interviews (Haron, Khalid, Ganesan, \& Fernando, 2017; Neale, 2006).

In this study, individual interview was carried out. The outcome of the interview is very informative and contains relevant data required for the study. The Group Chief Executive Officer (CEO) with manpower strength of approximately 10,000 , is the participant for this study. He is the subject matter expert and the right person to fulfill the objectives of research questions adequately. The outcome and analysis cannot be generalized, anyhow the findings served as very reliable reference.

\section{Data Analysis}

'Themes' are identified at the beginning of the process and are classified in qualitative research, and are used as element, descriptor, attribute and concept. Themes provide path to smoothen researchers to analyze for the answers of the study questions in a more structured manner, in a way as an implicit topic that organizes a group of repeating or relevant ideas accordingly (Ryan \& Bernard, 2003). Having themes is with the purpose that the research participants' subjective meanings and social reality are linked, structured and appropriately conveyed in the research report (Horsburgh, 2003), as data alone may not simply provide meaning and answers to the questions. Themes is formed to convey the meanings of data analysis. So, themes are constituted by a group of codes that have a common point of references and answers to the research questions based on the data collected, which is the interview and from literature review, and has a high level of generality that unifies ideas pertaining to the subject of inquiry (Bradley, Curry, \& Devers, 2007).

An interview session with the respondent on 6 April 2019 in Shah Alam, Selangor, on one to one and face to face session, was the beginning of the data gathering process. It went smoothly and was recorded for 23 minutes and 34 seconds. The audio record was sent to an online system called 'TranscribeMe! for transcribing the conversation record into text form. The full transcribed text is uploaded into ATLAS.ti application, as shown in Figure 3. Researcher opens the file in the system, go through the text and select one text passage (quotation) to another passage, which are relevant to the research questions. Researcher needs to define keywords for each passage and grouped them into themes and further followed by coding, as illustrated in Figure 4. 


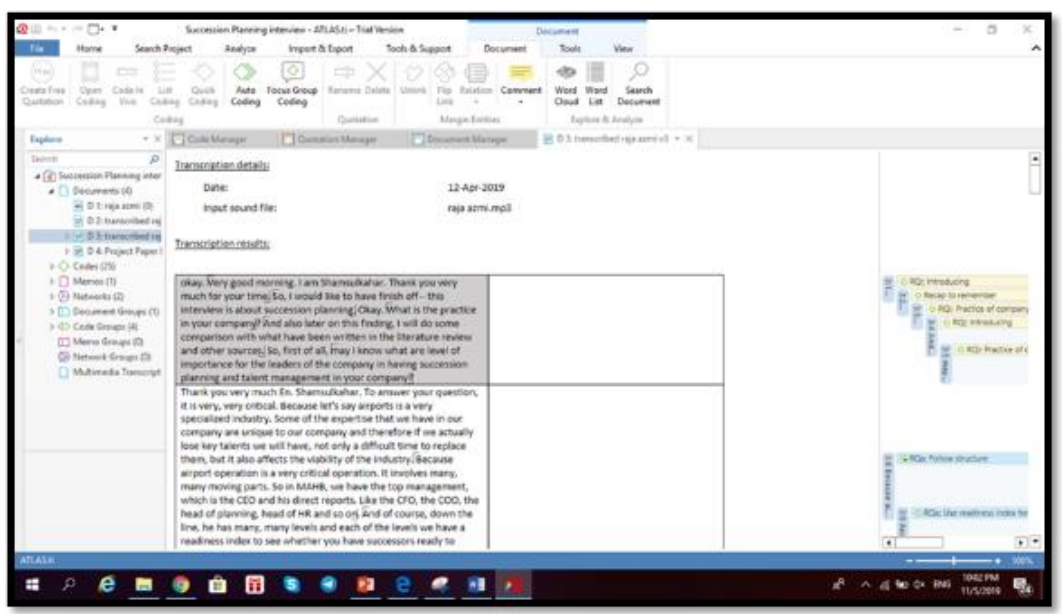

Figure 1: The Transcribed Voice Recording Document In The Software

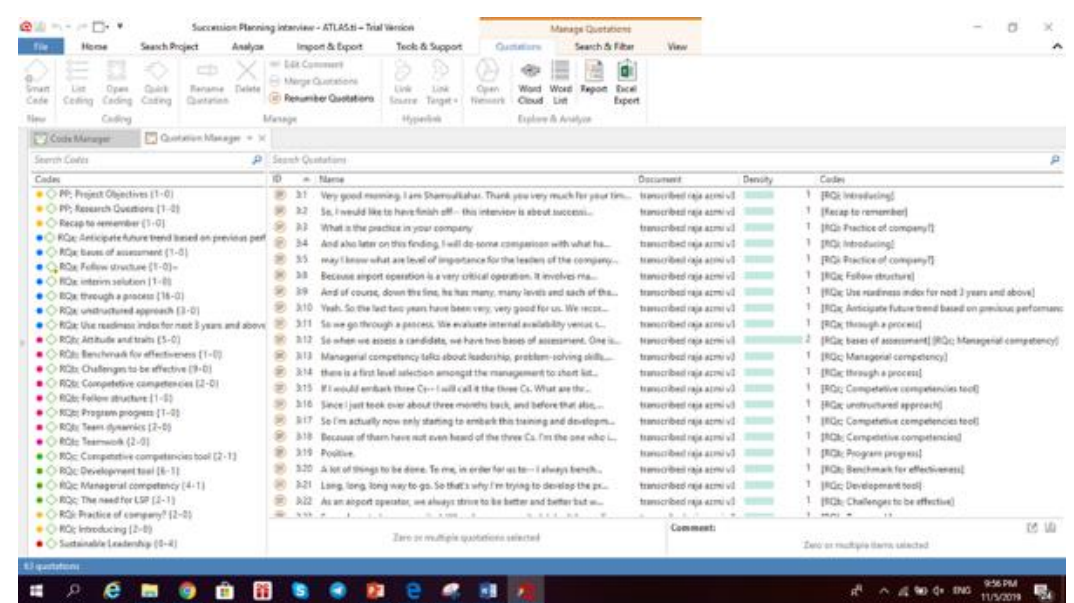

Figure 4: List of Codes

\section{Significant Statement (Quotations)}

The key component in qualitative data analysis is compiling and assigning quotations or statements to respective group of Codes, by using ATLAS.ti that can use and process discrete interaction with text or multimedia segments. Researcher and analysts can understand the full context of each single document with the help of those quotations, prior to consider categories that cut across the entire research project.

\section{Reliability of Research Instrument}

Initial research questions and objectives has been commented by two senior lecturers of UMP. Further to hat, the interview questions were reviewed by two other senior lecturers.

Feedback on the summary of research objectives, interview questions and framework by the participants was also taken into account during the presentation session in the International Conference on Business Intelligence, Industrial Engineering \& Management (ICBIIEM) 2018 on 11 December, 2018.

The interview voice recording was sent for transcription to an American based Transcribe.Me! software as shown in Figure 5, with minor manual edit on the unclear pronunciation and usage of Malay language.

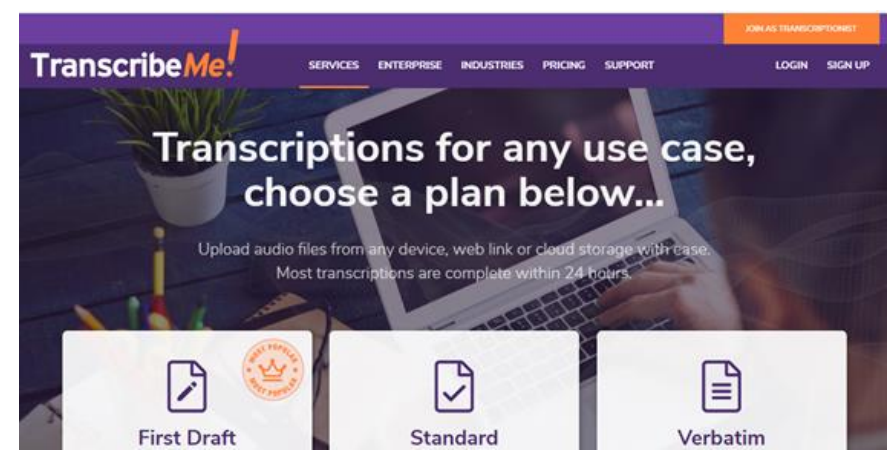

Figure 5: Transcribe.Me! software

Source: TranscribeMe! 
The use of ATLAS.ti application for analyzing and processing the qualitative gathered data with direct guidance by a certified ATLAS.ti trainer.

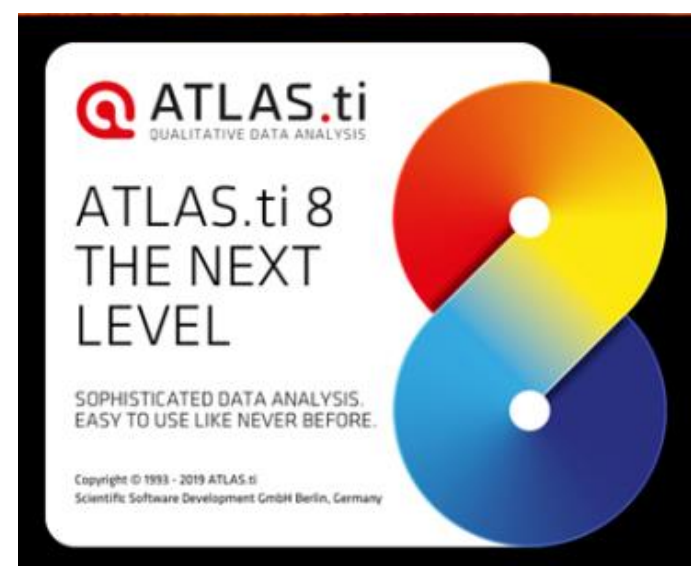

Figure 6: ATLAS.ti software

Source: ATLAS.ti

\section{Formation of Themes and Codes}

The main data collection in this Leadership Succession Planning is rooted in the interview with Group Chief Executive Officer, who is the lead of the company's business and operations. Researcher sought and presented the findings based on the questions (which were pointed based on the research objectives), grouped the data that answered the questions into themes and further into its respective codes, as shown in the table below.

There are two documents uploaded into ATLAS.ti for analysis, which are the transcribed interview document, and Literature Review of the research is also uploaded. The table shows how many quotations are there in each Codes. 'Through a Process' code scores the highest number in both Transcribed Voice Text and Literature Review, followed by 'Challenges to be effective'.

Table 1: Themes and Codes

\begin{tabular}{|c|c|c|c|c|c|}
\hline \multirow[b]{2}{*}{ Themes } & \multirow[b]{2}{*}{ Codes } & \multicolumn{2}{|c|}{ Number of } & \multicolumn{2}{|c|}{ Totals } \\
\hline & & 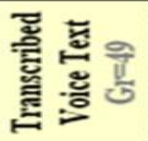 & 旁密竞 & 흘 & 总 \\
\hline \multirow{7}{*}{ 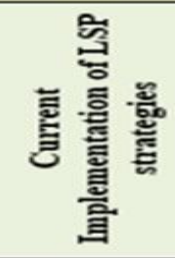 } & $\begin{array}{l}\text { - RQa; Anticipate future trend based on } \\
\text { previous performance. Gr=1 }\end{array}$ & 1 & o & 1 & \multirow{7}{*}{24} \\
\hline & - RQa; bases of assessment. Gr=1 & 1 & $\mathbf{O}$ & $\mathbf{1}$ & \\
\hline & - RQa; Follow structure. Gr=1 & 1 & $\mathbf{O}$ & 1 & \\
\hline & - RQa; interim solution. Gr=1 & 1 & O & 1 & \\
\hline & - RQa; through a process. Gr=16 & 12 & 4 & 16 & \\
\hline & - RQa; unstructured approach. $\mathrm{Gr}=3$ & 3 & O & 3 & \\
\hline & $\begin{array}{l}\text { - } \mathrm{RQa} \text { : Use readiness index for next } 3 \text { years } \\
\text { and above. Gr=1 }\end{array}$ & 1 & $\mathbf{O}$ & $\mathbf{1}$ & \\
\hline \multirow{8}{*}{ 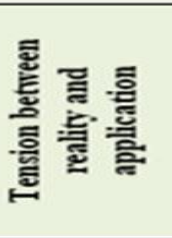 } & - RQb; Attitude and traits. Gr=5 & 3 & 2 & 5 & \multirow{8}{*}{23} \\
\hline & - RQb; Benchmark for effectiveness. Gr=1 & 1 & O & 1 & \\
\hline & - RQb; Challenges to be effective. Gr=9 & 9 & $\mathbf{0}$ & 9 & \\
\hline & - RQb; Competitive competencies. Gr=2 & 1 & 1 & 2 & \\
\hline & - RQb; Follow structure. Gr=1 & 1 & $\mathrm{O}$ & 1 & \\
\hline & - RQb; Program progress. Gr=1 & 1 & O & 1 & \\
\hline & - RQb; Team dynamics. Gr=2 & 1 & 1 & 2 & \\
\hline & - RQb; Teamwork. Gr=2 & 2 & O & 2 & \\
\hline \multirow{4}{*}{ 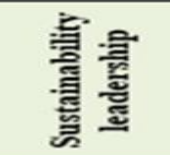 } & - RQc: Competitive competencies too1. Gr=2 & 2 & $\mathbf{O}$ & 2 & \multirow{4}{*}{14} \\
\hline & - RQc; Development tool. Gr=6 & 2 & 4 & 6 & \\
\hline & - RQc; Managerial competency. Gr=4 & 3 & 1 & 4 & \\
\hline & - RQC; The need for ISP. Gr=2 & 2 & 0 & 2 & \\
\hline \multicolumn{2}{|l|}{ Totals } & 48 & 13 & 61 & 61 \\
\hline
\end{tabular}

\section{Data Analysis Network Diagram}

Representation and exploration of conceptual structures is simplified and summarized using network illustration used in ATLAS.ti. Network diagram add a heuristic `right brain’ approach is used in qualitative analysis. A psychologist and Nobel Prize winner, Robert W.Sperry, according to a research in 1960s, suggests that the right brain is more intuitive and visual, and also connected to imagination, intuition, holistic thinking, rhythm, art and feelings visualization (Pietrangelo, 2017). Researcher can use the structural properties of code-networks to enhance the quotations retrieval, besides using 
the network for the visual design of theoretical models and 'mind mapping', for a summary view on the overall link of the themes, codes and quotation by the readers.

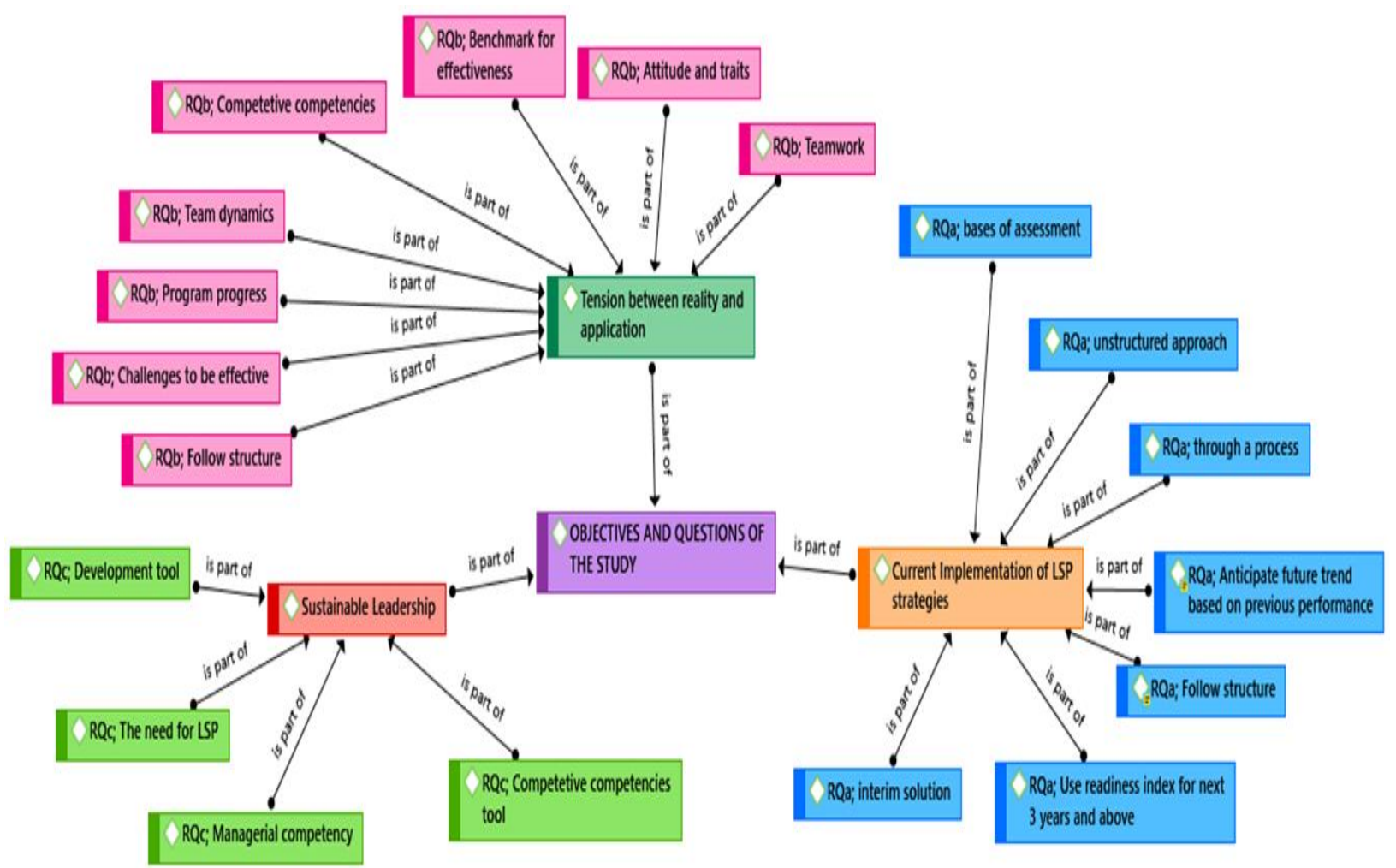

Figure 7: Network diagram of themes and codes

Each of the research themes which constitute part of the research objectives and questions, and list of codes that constituted each of the themes, is summarized in the network diagram as shown in Figure 7. Three themes are identified in answering the research questions, (i) Current Implementation of LSP Strategies, (ii) Tension between Reality and Application, and (iii) Sustainable Leadership. Codes are assigned in each of the themes. Some codes are relevant to more than one theme.

Theme: Current Implementation of SLP Strategies

An overview on 'Current Implementation of SLP Strategies' theme and those codes linked to it is shown in the network diagram in Figure 8, which further connected by list of selected quotation summary connected to each of the relevant code, with the time that respective statement was stated during the interview recording. 


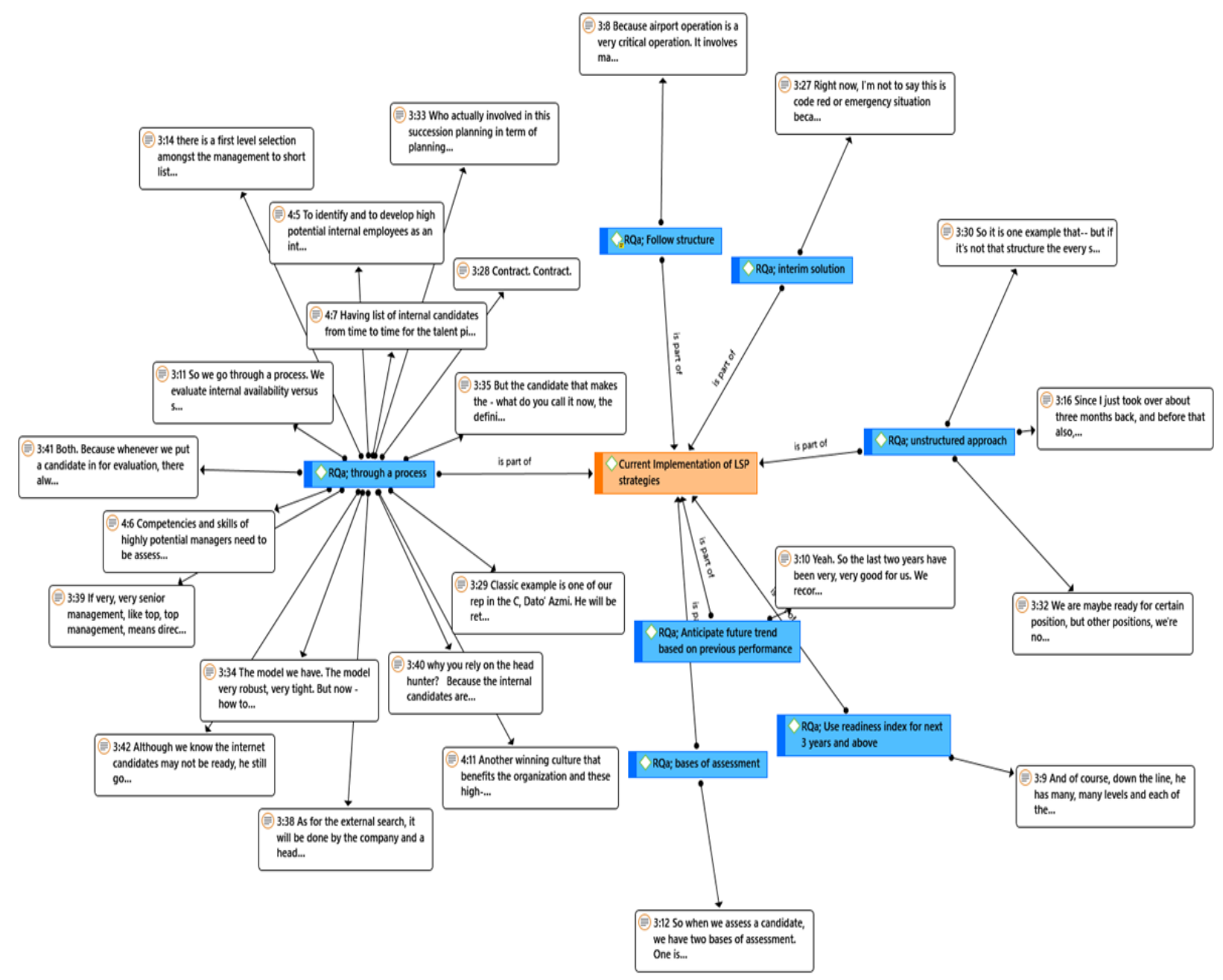

Figure 8: Current Implementation of SLP Strategies

Theme: Tension between reality and application

'Tension between reality and application' theme and those codes linked to it, is illustrated by the network diagram as shown in Figure 9, followed by list of selected quotation summary connected to each of the relevant code, with the time that respective statement was stated during the interview recording. 


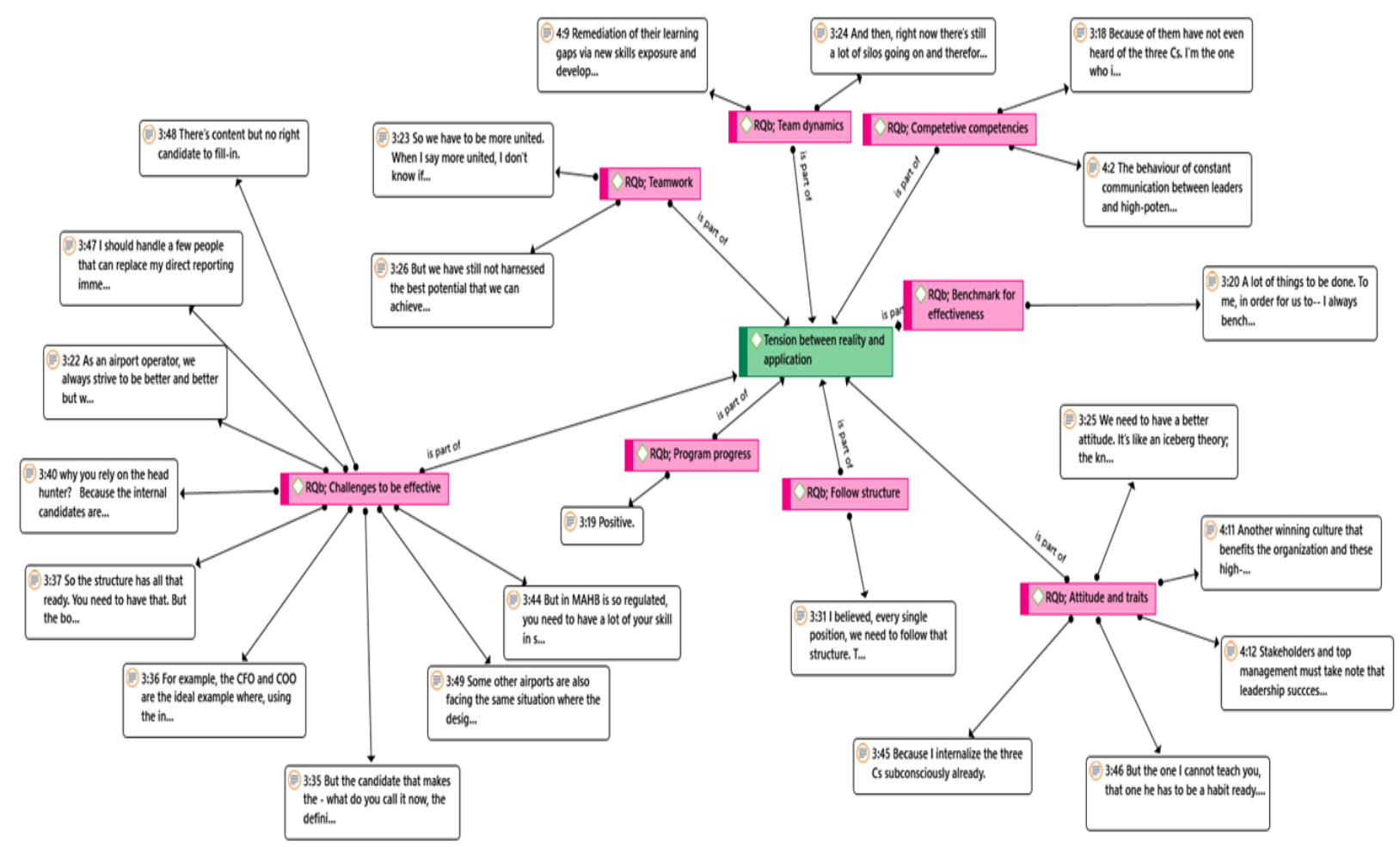

Figure 9: Tension between reality and application

Theme: Sustainability Leadership

'Sustainability leadership' theme and those codes linked to it, is illustrated by the network diagram Figure 10 below, and further connected by list of selected quotation summary whichconnected to each of the relevant code, with the time that respective statement was stated during the interview recording.

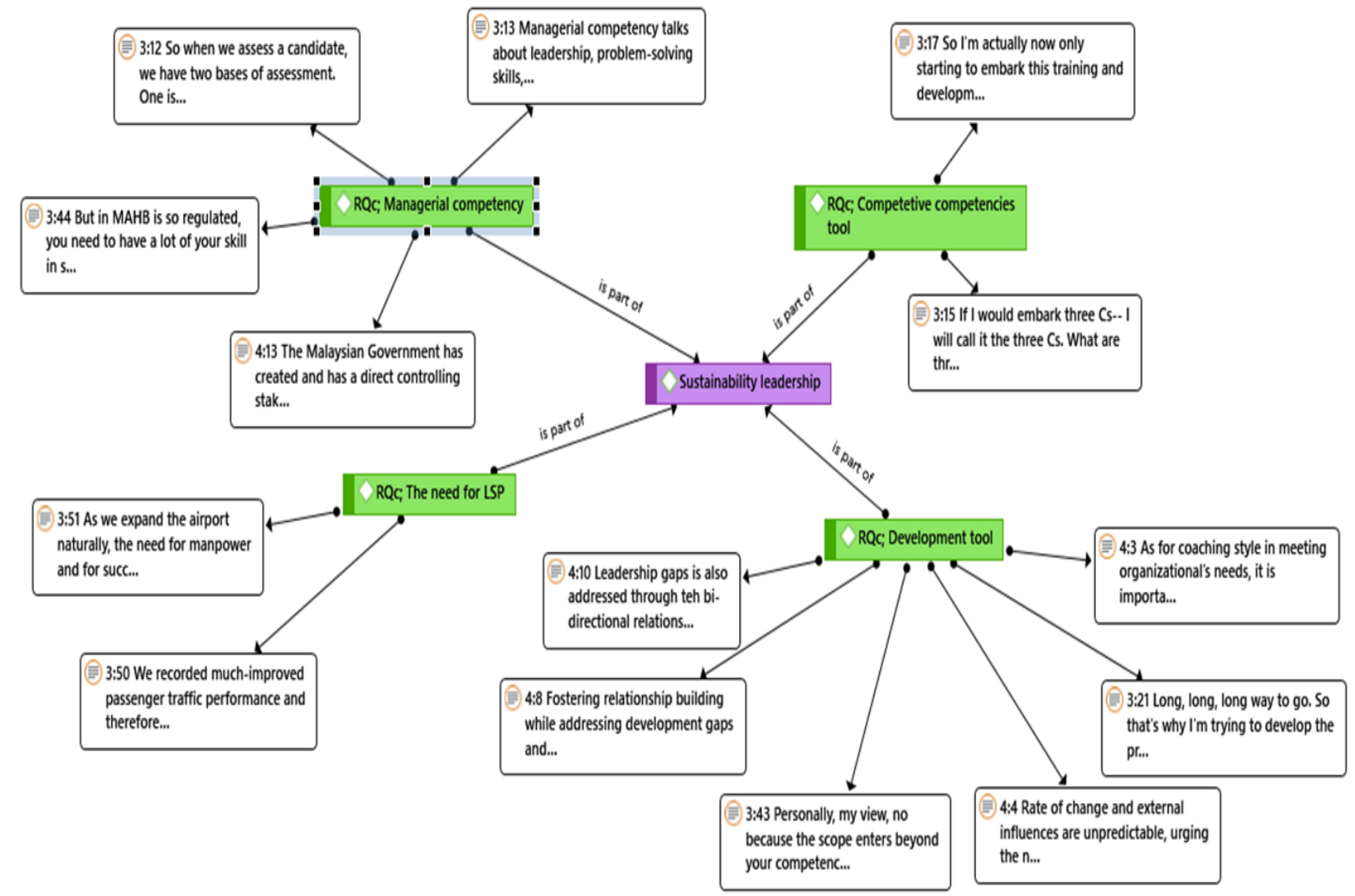

Figure 10: Sustainability Leadership 


\section{DISCUSSION}

The study on the factors influencing the effective leadership succession planning on a Malaysian GLC covers three main areas which are known as themes. The researcher highlighted the importance of leadership succession planning, particularly on the external factors that have the impact on the company's business direction and operation. World is currently facing the dynamism of technologies and applications, and the political climates such as change in the ruling government, impact of any major incidents like earthquake and many others, potential leaders of a business company must be quality of making right and fast decisions. Within the time constraint in conducting the study, the researcher managed to dig some valuable information that is beneficial theoretically (academic implication) and practically (managerial implication).

It is important to understand that the requirement for providing effective LSP in ensuring leadership quality and capability keeps changing in responding to the macroeconomic factors, the research on LSP needs to be carried out from time to time. Theories and literatures might be debatable after some period of time. The researcher conducted this study as to to give some ideas on the changes on the leadership aspects, for the academicians to blend the learning module to meet the industrial needs. The discussions are based on the overall analysis of data, as in the Attachment I.

\section{Limitation of Study}

Researcher had experienced some limitations in conducting the study which have the impact on the level of accuracy of the study's output or conclusion. The most critical limitation in conducting any study are time and references. Time constraint for the researcher to comply conduct the study within a semester, being a part time student. Time constraint is also experienced in scheduling for the interview with respondent, due to his hectic schedule to spend time for the interview.

Confidentiality of some operational information also contribute towards the limitation. Business organizations like the Government-Linked Companies, are not willing to share their approach due to highly competitive environment globally. Another limitation is, there is very minimal number of previous studies on LSP topic, as the result of the difficulties in getting information. This will limit the study on the gap to be analyzed. Researcher proceeded with the study despite those limitations, since LSP topic is very important for any organizations, particularly those have direct interest by the government. Researcher had also spent some extra effort and time to learn new application system for data analysis.

\section{Recommendation for Future Study}

As highlighted in the Implication section earlier, output or implication of the study has given valuable information to the LSP subject. Thus, it gives greater impactful information if a further and thorough study to be carried out, such as y having more respondents particularly C-levels, since they are the subject matter expert and have vast experiences in ensuring their organization to progress well and to meet stakeholders expectations. At the same time, a mixed research method can be conducted as well in order to come out with a more practical and accurate leadership succession planning strategies.

The combination of the above recommendations will yield a triangulation results that can give greater understanding and analysis on the shortcomings or challenges in having a comprehensive LSP and to sustain the company's performance in the long run. As this is qualitative study, the findings cannot be generalized into other industry or organization. More study need to be to other organization. To provide a matched analysis, future researchers can conduct research on other Government-Linked Companies as well. Even though the nature of business might be different among GLCs, C-level candidates share the about the same competencies and skills in managing their organizations and to remain competitive..

\section{CONCLUSION AND IMPLICATIONS}

Referring to section Research Aims and Objectives earlier, the objectives of this study have been achieved through the qualitative research methods as described in chapter Research Methodology. Interview and literature had been compiled and analyzed, as stated in Section Analysis, is done using ATLAS.ti analysis tool to sort out and to arrange the quotations or excerpt those relevant data into themes and codes. The outcome of the findings and analysis is obtained using this system.

The success of the study is contributed by the interview participant, who is chosen by the researcher due to the hia proven track record of performance and from a very dynamic organization, and at the same time, has to comply with the government strict policy, so that the interviewee's experiences and his way forward strategies can be learned by other practitioners, academicians and himself. It is beneficial to learn the challenges he has been facing, the areas that need to be focused and how he plan to overcome those shortcomings.

Conclusively, the study has given a good beginning exposure for further researches to come out with the realistic strategy sharing and theories that can be benefited by any organization, in order to ensure there is an effective LSP and continuous performance growth. The subject of this study will always subject to revision and improvement in lieu with the development of the technologies, borderless world, business dynamism and complexity of the overall system. 


\section{ACKNOWLEDGEMENT}

I wish to sincere thanks to my research supervisor, Dr. Suhaidah binti Hussain from the Faculty of Industrial Management, Universiti Malaysia Pahang, for the valuable guidance, expertise and knowledge sharing and encouragement throughout the research. She is very supportive who always ensure the progress of conducting and writing this research. She has introduced and recommended me to use ATLAS.ti software to analyze my collected qualitative data effectively. I would like to take this opportunity to express my warm thanks to my family for their understanding and moral support particularly it was very time consuming, to manage the time for family, work and research. I sincerely appreciate their unceasing encouragement, support, and attention that lead me toward the success of this research. I would like to express my sincerely appreciation to the Bank Rakyat for funding my participation in the presentation of my research paper in this FGIC 2nd Conference on Governance \& Integrity.

\section{REFERENCES}

Allio, R. J. (2012). Leaders and leadership - many theories, but what advice is reliable? Strategy \& Leadership, 41(1), 4-14. https://doi.org/10.1108/10878571311290016

Ariss, A. a., Cascio, W., \& Paauwe, J. (2014). Talent management: Current theories and future research directions. Journal of World Business, pp. 173-179.

Avey, J. B., Avolio, B. J., \& Luthans, F. (2011). Experimentally analysing the impact of leader positivity on follower positivity and performance. Leadership Quarterly, 22(2), 282-294.

Bass, B. M. (2008). The Bass Handbook of Leadership: Theory, Research, and Managerial Applications, 4th Ed. New York, NY: Free Press.

Beh. (2007). China International Conference "Implications of a Transforming China: Domestic, Regional and Global Impacts: International China World Conference, 1-36.

Beheshtifar, M. \&.-P. (2012). Leadership Development Activities. International Journal of Academic Research in Business and Social Sciences Vol. 2, No. 7, 387-393.

Bhawna, \& Gobind, \&. (2015). Research Methodology and Approaches. IOSR Journal of Research \& Method in Education (IOSRJRME), 5(3), 48-51.

Blattner \& Walter, J. -T. (2015). Creating and sustaining a highly engaged company culture in a multigenerational workplace. Strategic HR Review, 124-130.

Bocatto, E. \&. (2010). Family-Owned Business Succession: The Influence of Pre-performance in the Nomination of Family and Nonfamily Members: Evidence from Spanish Firms. Journal of Small Business Management, 48, 497-523.

Bradley, E. H., Curry, L. A., \& Devers, K. J. (2007). Qualitative Data Analysis for Health Services Research: Developing Taxonomy, Themes, and Theory. Health Services Research v42(4), 1758-72.

Brent, C. (2013). Succession Planning: Be proactive, not reactive. United Kingdom: : Ray and Berndtson Publishing.

Calareso, J. P. (2013). Succession planning. The key to ensuring leadership. Planning For Higher Education, 41(3), 27-33.

Carmeli, A., Schaubroeck, J., \& Tishler, A. (2011). How CEO empowering leadership shapes top management team processes: Implications for firm performance. Leadership Quarterly, 22(2), 399-411.

Centre for Public Policy Studies. (2006, January 5). CPPS Recommendations for the 9th Malaysia Plan: Overview and Details. Centre for Public Policy Studies.

Cho, Y. J., \& Poister, T. H. (2014). Managerial Practices, Trust in Leadership, and Performance. Public Personnel Management vol. 43, 179-196.

Chung, X. R.-N. (2012). Leadership succession and firm performance in an emerging economy: Successor origin, relational embeddedness, and legitimacy. Strategic Management Journal vol 34, 338-357.

Dewah, P., \& Mutula, S. M. (2014). Knowledge retention strategies in public sector organizations: Current status in sub-Saharan Africa. Information Development., 1-15.

Fink, D. (2011). Pipelines, pools and reservoirs: building leadership capacity for sustained improvement. Journal of Educational Administration, 49(6), 670-684.

Galagan, P. (2010). Bridging the Skills Gap: New Factors Compound the Growing Skills Shortage. American Society for Training \& Development.

García-Morales, V. J., Jiménez-Barrionuevo, M. M., \& Gutiérrez-Gutiérrez, L. (2012). Transformational leadership influence on organizational performance through organizational learning and innovation. Journal of Business Research, 65(7), 1040-1050.

Greenhalgh, N., \& Jantti, M. (2012). Leadership competencies: a reference point for development and evaluation. Library Management, 33(6/7), 421-428.

Hanson, B. (2013). The Leadership Development Interface: Aligning Leaders and Organizations towards More Effective Leadership Learning. Advances in Developing Human Resources, 15(1), 106-120.

Haron, H., Khalid, S. N., Ganesan, Y., \& Fernando, Y. (2017). A Handbook For Business Research Methods pg 26-27. Kuala Lumpur: Pearson malaysia Sdn Bhd.

Hayat, U. (2013). Malaysia's Khazanah: Not Just a SWF But a "Nation Building Institution". Kuala Lumpur: CFA Institute, url: https://blogs.cfainstitute.org/investor/2013/07/30/malaysias-khazanah-not-just-a-swf-but-a-nation-building-institution/.

Horsburgh, D. (2003). Evaluation of qualitative research. Journal of Clinical Nursing v12(2), 307-312.

Jing, F. F., \& Avery, G. C. (2016). Missing Links In Understanding The Relationship Between Leadership And Organizational Performance. International Business \& Economics Research Journal (IBER), 15(3), 107.

Lewis, R. E., \& Heckman, R. J. (2006). Talent management: A critical review. Human Resource Management Review, 16(2), 139154.

Malaysia National Economic Advisory Council. (2008). NEW ECONOMIC MODEL - Part I: Strategic Policy Directions, pg 54 \& pg 126. Kuala Lumpur: Percetakan Nasional Malaysia Berhad,

Metcalfe, A., \& Metcalfe, A. (2013). Reliability and validity of the "leadership competencies and engaging leadership scale". International Journal of Public Sector Management, vol. 26, 56-73. 
Mokhtar, A. (2005). The Malay way of business change. The Economist 376 (8440), p. 50, August 18

Moradi, M. R. (2014). Managers succession planning for human capital development. Advances in Environmental Biology, 8, 17761785 .

Neale, C. B. (2006). CONDUCTING IN-DEPTH - A Guide for Designing and. Watertown url: http://www2.pathfinder.org/site/DocServer/m_e_tool_series_indepth_interviews.pdf: Pathfinder International Tool Series.

Nold, H. (2016). The performance triangle: a model for corporate agility. Leadership \& Organization Development Journal, vol 3, 341 356.

Pietrangelo, A. (2017, January 18). Left Brain vs. Right Brain: What Does This Mean for Me? Healthline newsletter, pp. https://www.healthline.com/health/left-brain-vs-right-brain.

Quintana, C. D. (2014). Competencies which shape leadership. International Journal of Manpower, Vol. 35 Issue: 4, 514-535.

Rastogi, N., \& Trivedi, D. M. . (2016). Pestle Technique - a Tool To Identify External Risks in Construction Projects. International Research Journal of Engineering and Technology, 03(01), 384-388. Retrieved from www.irjet.net

Risher, H. (2015). Employers Need to Invest to Strengthen Performance Management. Compensation \& Benefits Review, 47(2), 5559.

Rovai, A. P., Baker, J. D., \& Ponton, M. K. (2014). Social Science Research Design and Statistics: A Practitioner's Guide to Research Methods and SPSS Analysis. Virginia USA: Watertree Press LLC.

Ryan, G. W., \& Bernard, H. R. (2003). Techniques to Identify Themes. Field Methods, v 15(1), 85-109.

Saratun, M. (2016). Performance management to enhance employee engagement for corporate sustainability. Asia-Pacific Journal of Business Administration, Vol. 8 Issue: 1, 84-102.

Sheth, M. (2016). How to achieve a win/win for both employees and corporates. Strategic HR Review, Vol. 15 Issue: 2, 70-75.

Stumpf, S. A., JR, W. G., Ehr, R. J., \& Dam, N. H. (2016). Leading to intrinsically reward professionals for sustained engagement. Leadership \& Organization Development Journal, Vol. 37 Issue: 4, 467-486 Stephen A Stumpf, Walter G Tymon JR, Robert J Ehr, Nick HM van Dam.

Stewart, C. (2016). How diverse is your pipeline? Developing the talent pipeline for women and black and ethnic minority employees. Industrial and Commercial Training, Vol. 48 Issue: 2, 61-66.

The SUN. (2017). Stringent Vetting Of GLC Heads. The SUN newspaper. Kuala Lumpur, Federal Territory, Malaysia: The SUN November 15

Tracy, S. J. (2013). Qualitative Research Methods: Collecting Evidence, Crafting Analysis, Communicating Impact. Arizona State: Chichester: Wiley-Blackwell.

Vietor, R. H. (2007). How Countries Compete: Strategy, Structure, and Government in the Global Economy. USA: Harvard Business School Press.

Yamkovenko, B., \& Hatala, J. P. (2015). Methods for Analysis of Social Networks Data in HRD Research. Advances in Developing Human Resources, 17(1), 40-56.

Zikmund, W. G., Carr, J. C., \& Griffin, M. (2013). Business Research Methods | 9th Edition. Boston, Massachusett: Cengaged

\section{APPENDICES}

\section{HOW DATA IS ANALYSED}

Theme: Current Implementation of LSP strategies.

Quotations from the interview in this sub-section are responding to the Research Question: How does the

Company carry out their current LSP strategies or program? Each selected quotation or statement is linked to the research objectives as elaborated in the Interpretive Meaning column in Table 4.1 below.

Table 4.1: Significant Statement and Meaning from Current Implementation of LSP Strategies Theme. Significant statement

Interpretative Meaning

\section{Current Implementation of LSP strategies}

- "Yeah. So the last two years have been very, very good for us. We recorded much-improved passenger traffic performance and therefore that resulted in us earning a great profitability and we anticipate this trend to continue in the next few years. So far yearon-year we have been recording growth. There is no year-on-year decline in passenger traffic volume hence the results have been very, very encouraging. Yeah. It's been positive”. Document Source: Transcribed Voice Text (3:10).
LSP current strategy practice is equipped with the ability to anticipate future trend based on previous performance. This is the only quotation this RQa code (refer to Error!

Reference source not found.).

- $\quad$ "So when we assess a candidate, we have two bases of
assessment. One is the technical competency and the other one is $\begin{aligned} & \text { bSP current strategy practice have } \\ & \text { competency of assessment on technical }\end{aligned}$




\section{Current Implementation of LSP strategies}

the managerial competency". Document Source: Transcribed

Voice Text (3:12). competency. This is the only quotation this RQa code
- "Because airport operation is a very critical operation. It involves many, many moving parts. So in <the Company>, we have the top management, which is the CEO and his direct reports. Like the CFO, the COO, the head of planning, head of HR and so on”. Document Source: Transcribed Voice Text (3:8).
LSP current strategy practice does have interim solution for the fulfilment of candidate. This is the only interview quotation for this RQa code cover them. Let's say, somebody leaves next week or crisis happen, the airport will not be at a standstill. But it is not ideal because I need to have a successor ready actually to take over, but I do not have a successor ready". Document Source: Transcribed Voice Text (3:27)

- "So we go through a process. We evaluate internal availability versus some resources externally. And from that pool, we will select those who are most eligible to fill up that position. But we never ignore internal candidates". Document Source: Transcribed Voice Text (3:11).

- "There is a first level selection amongst the management to short list candidates, namely me and the HR head. And then after that, we will recommend the candidates to the - what they call the - BNRC which is the Board Nomination Remuneration Committee. They will meet and they will interview those shortlisted candidates. And if they make the cut, they will go along with management recommendation. If they don't make the cut, in their point of view, they will start the process all over again". Document Source: Transcribed Voice Text (3:14).

- $\quad$ "Classic example is one of our rep in the C, Dato' Azmi. He will be retiring in about years' time. We've really identified three potential successors, and we are starting to train them. We are giving all the managerial development skill, coaching. We send coaches to them". Document Source: Transcribed Voice Text $(3: 29)$.

- "Who actually involved in this succession planning in term of planning and implementing it? HR. HR head". Document Source: Transcribed Voice Text (3:33).
LSP current strategy practice goes through a process. There are 12 quotations from the interview and four LR statement for this RQa code 


\section{Current Implementation of LSP strategies}

- "The model we have. The model very robust, very tight.

But now - how to say it? - The process is there. The content it's not there yet". Document Source: Transcribed Voice Text (3:34).

- $\quad$ "But the candidate that makes the - what do you call it now, the definition? - R2, R3, R4 readiness level, okay, we have not fill up the boxes nicely because there are some people who are not ready yet”. Document Source: Transcribed Voice Text (3:35). Also for code RQb; Challenges to be effective.

- $\quad$ "As for the external search, it will be done by the company and a head hunter? And a head hunter. And a headhunter". Document Source: Transcribed Voice Text (3:38).

- "If very, very senior management, like top, top management, means direct report to the CEO, mainly head hunter. But if it's a senior manager level, it's mixed. Some head hunter, some internal". Document Source: Transcribed Voice Text (3:39) - "Why you rely on the head hunter? Because the internal candidates are not ready. Because our succession planning process is not robust enough to make them ready". Document Source: Transcribed Voice Text (3:40). Also for Code RQb; Challenges to be effective.

- "Both. Because whenever we put a candidate in for evaluation, there always will be an internal candidate or two, right? And, see, when you do an evaluation, you do two. You do an interview evaluation and a psychometric test evaluation". Document Source: Transcribed Voice Text (3:41)

- "Although we know the internet candidates may not be ready, he still go through the process of interview as well as a psychometric test. The psychometric test is like a leadership-style test, whether you are a situation leader, you are a task leader, people person leader because even if he doesn't make the cut yet, at least from the psychometric test, he knows where to improve himself to make himself ready. The test itself would show whether he is ready or not to go for the-- what do you call it? Development. Development. Even if he's not ready now, at least his development plan is more clearly charted out from that result". Document Source: Transcribed Voice Text (3:42).

- To identify and to develop high potential internal employees as an integral tasks of organizational planning and 


\section{Current Implementation of LSP strategies}

performance (Risher, 2015; Yamkovenko \& Hatala, 2015).

Document Source: Literature Review

- $\quad$ Competencies and skills of highly potential managers need to be assessed accordingly and continuously, serve as critical components of LSP process (Moradi, 2014; Hanson, 2013). Document Source: Literature Review

- Having list of internal candidates from time to time for the talent pipeline creates good business sense. Top management should be willing to invest in application and synergistic practices for sourcing high potential internal talent through LSP, as social exchange does contribute towards this purpose .(Saratun, 2016) (Cho \& Poister, 2014). Document Source: Literature Review

- $\quad$ To another winning culture that benefits the organization and these high-potential employees can be generated via a cultivating replacement planning strategy (Sheth, 2016) (Nold, 2016). Document Source: Literature Review (also for RQb; Attitude and traits)

- "Since I just took over about three months back, and before that also, I think, for the seven months prior to that, so this is quite a new thinking from me. Previously, there isn't such a structured approach in this manner or that manner". Document Source: Transcribed Voice Text (3:16)

- "So it is one example that-- but if it's not that structure the every single position”. Document Source: Transcribed Voice Text $(3: 30)$

- $\quad$ "We are maybe ready for certain position, but other positions, we're not ready. So in short, our succession training process is not ideal yet". Document Source: Transcribed Voice Text (3:32)

- $\quad$ "And of course, down the line, he has many, many levels and each of the levels we have a readiness index to see whether you have successors ready to replace your position in two year time. And there are people ready in three year time and four year time and so on". Document Source: Transcribed Voice Text (3:9)

\section{Theme: Tension between reality and applications}

Quotations from the interview in this sub-section are responding to the Research Question: Why there are gap between the expectation and the outcome of LSP, and how effective is it? What does the literature express on succession planning? What are the issues or variables that are important determinants of effective implementation of LSP initiatives? Each selected quotation or statement is linked to the research objectives as elaborated in the Interpretive Meaning column in Table 4.2 below.

\section{LSP current strategy practice does} experience unstructured approach. There are three quotations from the interview for this RQa code

\footnotetext{
LSP current strategy practice uses readiness index for next 3 years and above in advance. There is one quotation from the interview for this RQa code
} 
Table 4.2: Significant Statement and Meaning from Tension between Reality and Application Theme.

\begin{tabular}{|c|c|}
\hline \multicolumn{2}{|c|}{ Tension between reality and application } \\
\hline - "We need to have a better attitude. It's like an iceberg theory; & Explaining \\
\hline the knowledge is the top side of iceberg. Attitude is the bottom of & importance to reduce the gap \\
\hline the iceberg. So your attitude can actually make a difference although & between reality and application in \\
\hline you may not enjoy some of the macroeconomic factors which are & term of attitude and traits. There is \\
\hline beyond our control like you mentioned". Document Source: & three quotation from the interview \\
\hline Transcribed Voice Text $(3: 25)$ & and two quotations from LR, for this \\
\hline - "Because I internalize the three Cs subconsciously already". & RQb code \\
\hline
\end{tabular}

Document Source: Transcribed Voice Text $(3: 45)$

- $\quad$ "But the one I cannot teach you, that one he has to be a habit ready. Habit. But in order to become habit, they must be exposed and so on". Document Source: Transcribed Voice Text (3:46).

- Another winning culture that benefits the organization and these high-potential employees can be generated via a cultivating replacement planning strategy. (Sheth, 2016) (Nold, 2016). Document Source: Literature Review. Also for code RQa; through a process.

- Stakeholders and top management must take note that leadership succession planning is very important due to the fact that their companies have committed, dedicated and high-functioning trustees who work toward great outcomes for the plan (Galagan, 2010; Bocatto, 2010) Calareso, 2013; Beheshtifar, 2012; Fink, 2011) (Brent, 2013). Document Source: Literature review.

- "A lot of things to be done. To me, in order for us to-- I always benchmark or set against Changi because Changi is the best airport in the world in terms of both what you call the ASQ ranking which is Airport Service Quality as well as the Skytrax ranking, they are always number one. So we have to benchmark. So if you ask me whether how I rate Malaysia Airports against Changi, these 3 Cs as example”. Document Source: Transcribed Voice Text (3:20).

- "As an airport operator, we always strive to be better and better but we are somewhat to face Malaysian environment is a bit more challenging because in Changi you are able to collect a lot more airport tax for any traveler. In Changi, all international travelers anyway are taxed at SingD 47 or equivalent 140 ringgit Malaysia. For us, when we travel to Singapore we only pay 35 ringgit airport tax. They collect four times more airport tax than us. And because of that they are able to refurbish and redo and regenerate the terminal much more frequently, they have much more money for training and development to upscale for new products and
Explaining how the gap between reality and application could be reduced by having a benchmark for effectiveness of the business operation and service. There is one quotation from the interview for this RQa code

Explaining how the gap between reality and application could be reduced by overcoming the challenges to be effective. There are nine quotations from the interview and one excerpt from LR for this $\mathrm{RQb}$ code 
so on. We want to get that as well but our environment is so regulated, difficult to increase airport tax. So it is not an airport to airport comparison. If you give me the same airport tax as Changi, of course, I can do it like Changi”. Document Source: Transcribed Voice Text (3:22).

- "But the candidate that makes the - what do you call it now, the definition? - R2, R3, R4 readiness level, okay, we have not fill up the boxes nicely because there are some people who are not ready yet". Document Source: Transcribed Voice Text (3:35). Also for code RQa; through a process.

- "For example, the CFO and COO are the ideal example where, using the internal model of readiness, the internal candidate is not ready. And therefore, immediately, it triggers an external search". Document Source: Transcribed Voice Text (3:36).

- $\quad$ "So the structure has all that ready. You need to have that. But the boxes or the actual not fill up". Document Source: Transcribed Voice Text (3:37).

- "Why you rely on the head hunter? Because the internal candidates are not ready. Because our succession planning process is not robust enough to make them ready". Document Source: Transcribed Voice Text (3:28). Also for code RQa; through a process.

- $\quad$ "But in <the Company $>$ is so regulated, you need to have a lot of your skill in stakeholder management". Document Source: Transcribed Voice Text (3:44). Also for RQc; Managerial competency.

- $\quad$ "I should handle a few people that can replace my direct reporting immediately, right? But not quite yet, which shows that our process is still process-oriented. I mean, but not enough contentoriented”. Document Source: Transcribed Voice Text (3:47).

- “There's content but no right candidate to fill-in". Document Source: Transcribed Voice Text (3:48).

- "Some other airports are also facing the same situation where the design capacity is now been overtaken by the actual capacity. And therefore we need to expand the airport. As we expand the airport naturally, the need for manpower and for succession planning becomes even more critical". Document Source: Transcribed Voice Text (3:49). 


\section{Tension between reality and application}

- "Because of them have not even heard of the three Cs. I'm the one who introduced three Cs. So to answer your question, no. I don't think it is so robust yet, this application". Document Source: Transcribed Voice Text (3:18).

- The behavior of constant communication between leaders and high-potential employees linked and drives to the business needs affect its efficiencies and effectiveness, leads towards win-win workplace climate .(Metcalfe \& Metcalfe, 2013)(Stumpf, JR, Ehr, \& Dam, 2016; Blattner, 2015; Quintana, 2014)”. Document Source: Literature review.

- "I believed, every single position, we need to follow that structure. Then it's more organized". Document Source: Transcribed Voice Text (3:31).
Explaining how the gap between reality and application could exist if the Company is unprepared to have the skills in competitive competencies. There is one quotation from the interview and one from $\mathrm{LR}$, for this RQb code
• "Positive". Document Source: Transcribed Voice Text (3:19).
Explaining how the gap between reality and application could be reduced if the Company follow the current structure of LSP. There is one quotation from the interview for this RQb code

Explaining progress of LSP
program in reducing the gap between reality and application. There is one quotation from the interview for this RQb code

Explaining shortcoming in the team dynamics, in reducing the gap between reality and application. There is one quotation from the interview and one from LR, for this RQb code and development, improves performance where they will become more promotable employees thus creating a win-win culture for the company and cultivating leadership skills makes employees from degrees of potential to emerge and shape as leaders (Jing \& Avery, 2016). Document Source: Literature review

- $\quad$ "So we have to be more united. When I say more united, I don't know if it is connected with succession planning but we cannot have too much silo mentality. We need to work more as a team". Document Source: Transcribed Voice Text (3:23).

- But we have still not harnessed the best potential that we can achieve shift together as a team". Document Source: Transcribed Voice Text (3:26).
Explaining how to reduce the gap between reality and application of LSP by having to include teamwork. There are two quotations from the interview for this RQb code 


\section{Theme: Sustainability leadership.}

Quotations from the interview in this sub-section are responding to the Research Question: How succession planning will be able to prepare the next generation of CEO and general managers to be competent and able to function on the next higher level of management? What are the most important success factors that will have a positive effect on sustaining companies performance? Each selected quotation or statement is linked to the research objectives as elaborated in the Interpretive Meaning column in

Table 4.3 below.

Table 4.3: Significant Statement and Meaning from Sustainability Leadership Theme Significant statement Interpretative Meaning Sustainability Leadership

\begin{tabular}{ll}
\hline & \multicolumn{3}{c}{ Sustainability Leadership } \\
\hline$\bullet \quad$ "If I would embark three Cs-- I will call it the three Cs. What & Explaining how LSP can be \\
are three Cs? Number one, in this future of work where things are & effective through competitive \\
getting more and more competitive, they need to have - to me - & competencies tool as to ensure \\
three Cs which are number one, critical problem-solving-- critical & sustainability leadership. There are \\
thinking, sorry, critical thinking skills, means higher order & two quotations from the interview \\
thinking skills. Number two, the ability to solve complex & for this RQc code
\end{tabular}
problems. So complex problem-solving skill, the second C. And the third $\mathrm{C}$ is what $\mathrm{I}$ call a competitive culture. It means you need to have a competitive attitude. So these are some of-- apart from the usual technical skill, I would assess the candidate on these three attributes." Document Source: Transcribed Voice Text (3:15).

- $\quad$ "So I'm actually now only starting to embark this training and development programs in order to sharpen the three Cs". Document Source: Transcribed Voice Text (3:17).

- "Long, long, long way to go. So that's why I'm trying to develop the programs whether using external help or in-house in order to bridge that gap". Document Source: Transcribed Voice Text (3:21).

- $\quad$ "Personally, my view, no because the scope enters beyond your competency skill but also a lot on stakeholder management in terms of managing various ministries. And, somehow, maybe in a way I am also, in a way, I should do my part more by bringing them along with me so that I can be sort of training them, coaching them". Document Source: Transcribed Voice Text (3:43).

- "As for coaching style in meeting organizational needs, it is important for the top management to leverage it to motivate and develop future leaders, and executive coaching is one of the most effective method for developing high potential internal managers for multiple job levels and promotions (Chung, 2012)". Document Source: Literature review (4:3).
Explaining how LSP can be effective through development tool as to ensure sustainability leadership. There are two quotations from the interview for this RQc code 


\section{Sustainability Leadership}

- Rate of change and external influences are unpredictable, urging the need for organizational agility that influence internal operation disruption (Bass, 2008; Ariss, Cascio, \& Paauwe, 2014) (Jantti \& Greenhalgh, 2012).

- Fostering relationship building while addressing development gaps and improving connection between performance and potential, can be developed during one-to-one session, as a transactional exchange of information between the top management and those high potential employees (Allio, 2012).

Document Source: Transcribed Voice Text (4:8).

- Leadership gaps is also addressed through the bi-directional relationship between them and top management, as they are to be accountable for sharpening, training and development of qualified high-potential managers though succession planning. (Saratun, 2016)(Stewart, 2016) (Quintana, 2014) (Dewah \& Mutula, 2014)

(Blattner, 2015) (Moradi, 2014). Document Source: Transcribed Voice Text (3:10).

- So when we assess a candidate, we have two bases of assessment. One is the technical competency and the other one is the managerial competency". Document Source: Transcribed Voice Text (3:12). Also for Code RQa; bases of assessment.

- "Managerial competency talks about leadership, problemsolving skills, commercial orientation, and so on". Document Source: Transcribed Voice Text (3:13).

- $\quad$ "But in $<$ the company $>$ is so regulated, you need to have a lot of your skill in stakeholder management". Document Source: Transcribed Voice Text (3:44). Also for Code RQb; Challenges to be effective.

- The Malaysian Government has created and has a direct controlling stake in GLCs and the companies have a primary commercial objective. Document Source: Literature review (4:13).

Explaining how LSP can be
effective through managerial
Competency as to ensure
sustainability leadership. There are three quotations from the interview for this RQc code 
Sustainability Leadership

- "As we expand the airport naturally, the need for manpower leadership. There are two quotations and for succession planning becomes even more critical". from the interview for this RQc code 